\title{
AC 2011-2621: LESSONS LEARNED ON THE REDESIGN OF CONTENT AND LEARNING STRATEGIES FOR AN INTRODUCTORY COURSE TO CONSTRUCTION IN CIVIL ENGINEERING
}

\section{David Grau, The University of Alabama}

David Grau is an Assistant Professor at The University of Alabama. Recently, his work in the field of engineering education has focused on investigating the barriers and opportunities for the integration of best construction engineering practices into the curricula of higher education colleges and universities in North America. In addition, Dr. Grau has investigated the impact of a continuous training program in the discipline of construction engineering on the learning and work behavior of practicing engineers in the construction workforce. Currently, he investigates the effect of a novel program to increase the retention of first-year undergraduate students enrolled in an engineering college. The program also aims at increasing engineering student success, enhancing the sense of community and belonging by the students, and improving the transfer of knowledge in the engineering disciplines. In order to succeed in his research endeavors, Dr. Grau frequently collaborates with social scientists and educators. Prior to his academic career, he worked for more than seven years both leading an engineering department and managing complex industrial projects in South and Central America, and Europe. He is a registered Industrial Engineer in Spain and holds both a M.S. and a Ph.D. from the University of Texas at Austin.

\section{Guillermo Mejia}




\section{LESSONS LEARNED ON THE REDESIGN OF CONTENT AND LEARNING STRATEGIES FOR AN INTRODUCTORY COURSE TO CONSTRUCTION IN CIVIL ENGINEERING}

\section{Introduction}

There is an evident relationship between the practices of the civil engineering profession and the development of a country. Besides economic development, civil engineering facilitates growth and safety of a society, mainly through the design and construction of a country's infrastructure. Even more, this influence is greatly noticeable in Latin- American countries with emerging economics, such as Colombian case. Awareness of this relevance, Colombian government has adopted educational policies with particular emphasis on the revitalization of the engineering education with the aim to increase its indexes of economic growth through a sustainable and large infrastructure system (Caro 2003 ${ }^{1}$ ). Whereby, the Colombian Association of Faculties of Engineering (ACOFI) and Colombian Institute for Higher Education (ICFES) have called for the excellence and quality in the education of engineering. Particularly, ACOFI $\left(2006^{2}\right)$ suggests a serious curricular modernization of the engineering programs, the international homologation of the programs, and the improvement of the teaching strategies. Because, the traditional education methods, courses, and programs in engineering do not effectively satisfy the current and future needs of the industry and the society that they serve. But, some concerns arise in these emerging economic contexts: How must the construction courses be in order to face these new challenges? How much do these courses meet the current country's needs? How does student respond to new strategies implemented in class? How to assess the course improvements in order to correct timely those ineffective strategies? This article shows the preliminary results of a study that investigates the redesign of the content and the learning strategies of the course Introduction to Construction. This article shows the preliminary results of a study that investigates and assesses the redesign of the content and the learning strategies of Introduction to Construction course. The course is offered by the Department of Civil Engineering at The Universidad Industrial de Santander (UIS) -Colombia. The following sections of this paper cover the study objectives and methodology, the initial conditions of the course, improving the course syllabus, improving the instruction strategy, evaluation of course improvements effectiveness, and learned lessons and conclusion.

\section{Study Objectives}

This study focuses on the redesign of the content and the learning strategies of the course Introduction to Construction, with the aim to meet the current needs of the Colombian context, besides enhancing the students' academic performance as an acceptation indicator of these new strategies implemented in class. The overreaching goal of this study is to assess how to prepare the students for the technical challenges and management responsibilities that they will need to embrace, in the years to come, for the sustainable development of Colombian infrastructure system.

\section{Methodology}


In order to satisfy these objectives, a sequential-exploratory-combined research methodology was implemented for this study. This research method allows the collection, analysis, and interpretation of information by a combination of qualitative and quantitative methods within the same study (Creswell 1999 ${ }^{3}$; Morgan 1998 ${ }^{4}$ ). This method uses qualitative data that may be collected and analyzed separately from the quantitative data, giving diverse perspectives of the collected information and a better understanding of a phenomenon of study. Two sequential stages define the methodology of the study: a) an initial phase in which qualitative data on the key requirements for re-designing the course syllabus and instruction strategy was collected and analyzed, and b) a second phase in which the effectiveness of the proposed instruction approach was evaluated and statistically validated with quantitative data. The outcomes of the initial phase are both a set of fundamentals components that any course syllabus of introduction to construction must cover and the suggestion of an instruction strategy that meets the country's current needs. The outcome of the second phase is a measure of effectiveness of these improvements through enhancing student performance in class.

\section{Initial conditions of the course}

The previous conditions of the course Introduction to Construction may be summarized in two components: the syllabus and its instruction strategy. The syllabus was broken down in 16 weeks of class throughout an academic term and taught around a single major topic on construction management: construction budget and costs. This topic was approached in an isolated manner without linking to other fundamentals of construction management such as planning and scheduling. Each week had two class sections of two hours each. The traditional lecture class was the instruction strategy, where the lecturer explained basic concepts about estimating costs in construction projects and the students applied those cost fundamentals by undertaking a semester's project on the budget of a construction project. The grading system was basically based on three exams and the semester's project with a numerical scale ranging from 0 to 5 , where the approval grade was 3. There was a persistent problem regarding the students' performance in class that worried to the civil engineering department due to feeble averages achieved by students. The semester that references this situation showed the following averages, summarized in Table 1. The mean final grade of the course was acceptable with a value of 3.22 over 5.0; the mean final grade of the exam component was less than acceptable with 2.82 over 5.0; and the mean final grade of the semester's project was also acceptable with 3.75 over 5.0. The variability measures showed a noticeable dispersion index, and even more in the written exams component (see Table 1). Because of these feeble indexes of the students' performance in class, the civil engineering department made a decision to look for a solution strategy that boosts the students' performance of the Introduction to Construction course. To meet this need, a study about redesign and improvements strategies for the course was undertaken by a research team leaded by the course's professor but with an approach contextual rather than punctual, that looks for a significant contribution to the economic and social Colombian context, besides boosting the performance of the students.

Table 1 Performance indexes of reference semester 


\begin{tabular}{lr}
\hline Number of students & 45 \\
Mean -Course final grade & 3.22 \\
StDev & 0.6007 \\
CoefVar & 18.68 \\
Mean -Written exams final grade & 2.82 \\
StDev & 0.7880 \\
CoefVar & 27.99 \\
Semester's project final grade mean & 3.75 \\
StDev & 0.5991 \\
CoefVar & 15.97 \\
\hline
\end{tabular}

\section{Improving the course syllabus}

According to this study methodology, an initial phase in which qualitative data on the key requirements for re-designing the course syllabus and instruction strategy was collected and analyzed. In order to update the course syllabus to the needs of the society and current state of knowledge of the profession, an extensive literature review (inclusive of recommendations by trade associations in education) identified the current and relevant needs of the society and the industry -indirect beneficiaries of the civil engineering education. This review also included educational policies and industry trends. Additionally, an open and another structured surveys were undertaken with the students of construction classes in the civil engineering department at UIS. As an outcome of this study phase, the syllabus was structured in three thematic areas: planning, scheduling, and cost estimating. These concepts were designed to be integrated during the instruction of the course with a productivity improvement focus, as suggested by ACOFI $\left(2006^{2}\right)$ and indicated by Chinowsky $\left(2000^{5}\right)$. Alike, findings from the surveys showed that students' expectations regarding the construction course bear the same perspective oriented into current topics with applicability to real situations in the Colombian context (Acevedo 2007 ${ }^{6}$ ). Also, analysis and decision making computational and manual tools were integrated in the course in order to significantly enhance the students' cognition and skills, and provide them with an integral experience (ACOFI 1996 ${ }^{7}$ ). Finally, the course syllabus was integrated with the institutional development plan of the university between 2008 and 2018 (UIS $2007^{8}$ ), which emphasizes a global approach to the content and methods of instruction of the courses.

\section{Improving the instruction strategy}

Sequentially, this first stage covered the instruction strategy analysis whose improvement was based on students' and professors' feedback. Hence, three data collection tools allowed the definition of the key instruction strategies to enhance the academic performance of the students. The findings of an open survey, a structured survey, and a Test of Felder applied to three different samples, reflected the students' perceptions, which were analyzed and adapted to deliver the course syllabus.. The survey sample included students officially registered within the courses of the construction area in the school of civil engineering.. First, the open survey collected the preferences and suggestions of the students with respect to the methodology that had been used in the course. The open survey had 38 students representing the $70 \%$ of participation. Four criteria were defined to evaluate the perception of the students: class 
instruction, independent work, exams, and teaching style. The student responses described and commented their experiences, thoughts, and suggestions for each of them. The answers were classified and grouped by affinity for their posterior analysis. An analysis of this survey results revealed that students prefer the learning methodologies that promote self-learning, interrelate theory and practice, tackle innovative construction and management topics. Additionally, the results highlighted that the students prefer to approach the class content, exams, and assignments based on real construction cases, data, and situations. Second, the structured survey collected the student perceptions about some teaching and learning methods, as also about current study conditions in its daily learning processes. The structured survey had 41 students with the $71 \%$ of participation. Table 2 shows the time commitments of the students. The $44 \%$ of the students were actively working. The $12 \%$ of the students attended between three to four courses simultaneously during the semester -the $22 \%$ took five courses, and the $66 \%$ between six to eight courses. Finally, the test of Felder that classifies the students' learning styles had a total of 126 students participating, whose composition is summarized in Table 3. Table 4 summarizes the data obtained from the test of Felder about the student learning styles. These findings shows that the students want to base their knowledge on concrete knowledge rather than on abstract logic, and to get the understanding of a topic from the specific to the general concepts. For that reason, the education-learning strategies that need to be provided in the course should involve practical exercises, articulated to the reality, to strengthen his knowledge. The learning strategy of our proposal was integration of practical workshop as a method of instruction to consolidate the students' knowledge and skills, and thus to enhance their performance. The workshops included practical exercises and were articulated based on real construction scenarios. In detail, the workshop was observed as a key tool that would: a) consolidate principles and skills; b) provide an understanding of the implications (cost, schedule, and planning) of decision making processes; c) provide an opportunity for the integration of advanced computing tools; d) integrate real construction data into the learning environment of the students; and e) enhance the communicate skills of the engineers.

Table 2. Time dedication of students

\begin{tabular}{lccccc} 
& & & \multicolumn{3}{c}{$\begin{array}{c}\text { Number of courses attended } \\
\text { simultaneously in the semester }\end{array}$} \\
\cline { 2 - 6 } Students & Additional work activity & No & 3 or 4 & 5 & 6,7 or 8 \\
\hline Yes & & $7 \%$ & $10 \%$ & $27 \%$ \\
With labor activity & & & $5 \%$ & $12 \%$ & $39 \%$ \\
Without labor activity & \multirow{2}{*}{$56 \%$} & $12 \%$ & $22 \%$ & $66 \%$ \\
\hline
\end{tabular}

Sample size: 41 students

Table 3. Sample distribution (test of Felder)

\begin{tabular}{lccc} 
& $\begin{array}{c}\text { Students } \\
\text { Enrolled }\end{array}$ & \# Respondents & $\begin{array}{c}\text { Participation } \\
\text { Percentage }\end{array}$ \\
\hline Undergraduate Course I & 77 & 63 & $82 \%$ \\
Undergraduate Course II & 58 & 46 & $79 \%$ \\
Graduate Course & 22 & 17 & $77 \%$ \\
Overall & 157 & $\mathbf{1 2 6}$ & $80 \%$ \\
\hline
\end{tabular}


Table 4. Learning styles of the students in construction class

\begin{tabular}{llcc}
\hline Dimension & Characteristic & \# Students & $\begin{array}{c}\text { Percentage } \\
\%\end{array}$ \\
\hline \multirow{5}{*}{ Perception } & Very sensitive & 12 & $10 \%$ \\
& Sensitive & 44 & $35 \%$ \\
& Intuitive & 8 & $6 \%$ \\
& Neutral & 62 & $49 \%$ \\
\hline \multirow{5}{*}{ Reception } & Very visual & 35 & $28 \%$ \\
& Visual & 45 & $36 \%$ \\
& Verbal & 1 & $1 \%$ \\
& Neutral & 45 & $35 \%$ \\
\hline \multirow{5}{*}{ Processing -referenced to student } & Very active & 8 & $6 \%$ \\
& Active & 38 & $30 \%$ \\
& Reflexive & 7 & $6 \%$ \\
Processing -referenced to & Neutral & 73 & $58 \%$ \\
\hline learning method & Very sequential & 5 & $4 \%$ \\
& Sequential & 30 & $24 \%$ \\
& Global & 14 & $11 \%$ \\
\hline
\end{tabular}

Sample size: 126 students

\section{Evaluation of course improvements effectiveness}

According to this study methodology, the second stage measured the effect of the new syllabus and instruction strategy on the students' performance. This evaluation was accomplished through the students' final grades in class. A quasi-experimental design was used to measure the effectiveness throughout a continuous period of time, according to recommendations of Houser $\left(2009^{9}\right)$, Creswell $\left(2005^{10}\right)$, and Shadish et al. $\left(2002^{11}\right)$. Thus, the experiment extended four consecutive academic terms -i.e., in this order, semester-A, semester-B, semester-C, and semester-D. The results of the effectiveness of the course's improvements were compared by analyzing the performance of the students in the class throughout these consecutive semesters.

The conditions of each assessed semester, that represent the controlled variables in the study, were characterized as follows: the first semester (semester-A) was delivered with the previous syllabus design, with the previous instruction strategy, and a grading system based on exams and semester's project; the second semester (semester-B) was delivered with new syllabus, with the previous instruction, and also graded with exams and semester's project; and lastly, semester-C and semester-D were delivered with the new syllabus design and the workshops as additional instruction strategy, besides taking account the workshops as additional component in the grading system and independent of the exams and the semester's project. Likewise, the response variables observed and analyzed through all four semesters were: exams and semester's project. Their final grades were compared and analyzed looking for some sign of influence of the syllabus design and workshops on the student's performance. Table 5 summarizes the conditions under study of all four semesters. On the other hand, in order to control external variables that could affect the assessment outcomes, factors such as classroom, instructor, class time, among others, were kept up with unchangeable conditions through the academic terms of the study, as much as it were possible. And, regarding the factor pre-knowledge of the student, this factor was 
indirectly controlled in the study taking account of at least three measurements with the improvements implemented in class, to observe and analyze the students' final grades and identify potential threats of reliability and validity.

Table 5. Conditions of each assessed semester

\begin{tabular}{|c|c|c|c|c|}
\hline \multirow[b]{2}{*}{ Response Variable } & \multicolumn{4}{|c|}{ Controlled Variables } \\
\hline & Semester A & Semester B & Semester C & Semester D \\
\hline $\begin{array}{l}\text { Level of knowledge } \\
\text { Exams- final grades } \\
\text { Level of skills } \\
\text { Semester's Project } \\
\text { - final grades }\end{array}$ & $\begin{array}{l}\text { Previous content } \\
\text { Previous instruction }\end{array}$ & $\begin{array}{l}\text { New syllabus } \\
\text { Previous instruction }\end{array}$ & $\begin{array}{l}\text { New syllabus } \\
\text { Workshops }\end{array}$ & $\begin{array}{l}\text { New syllabus } \\
\text { Workshops }\end{array}$ \\
\hline
\end{tabular}

The variable exams, measured the level of knowledge gained as consequence of the course's improvements implemented in class. As shown on the Table 4, these measures were taken through the students' final grades of their written exams under four possible scenarios. The grading scale ranged from 0 to 5 with an approval grade 3 . The final grades of exams in the semester-A were obtained in the course taught with the previous syllabus and the previous instruction strategy. These final grades were compared with the final grades of the exams under the semester B scenario, where the course was taught with the new syllabus and the previous instruction strategy. Likewise, these final grades were compared with the final grades of semester-C and semester-D, which were taught with the new syllabus and the workshops as learning strategy for reinforcement. According to the variance analysis of the variable exams, statistically there is evidence of difference between the means of the exam final grades of these four scenarios $(p<0.05)$ as theirs confidence intervals show in Figure 1.

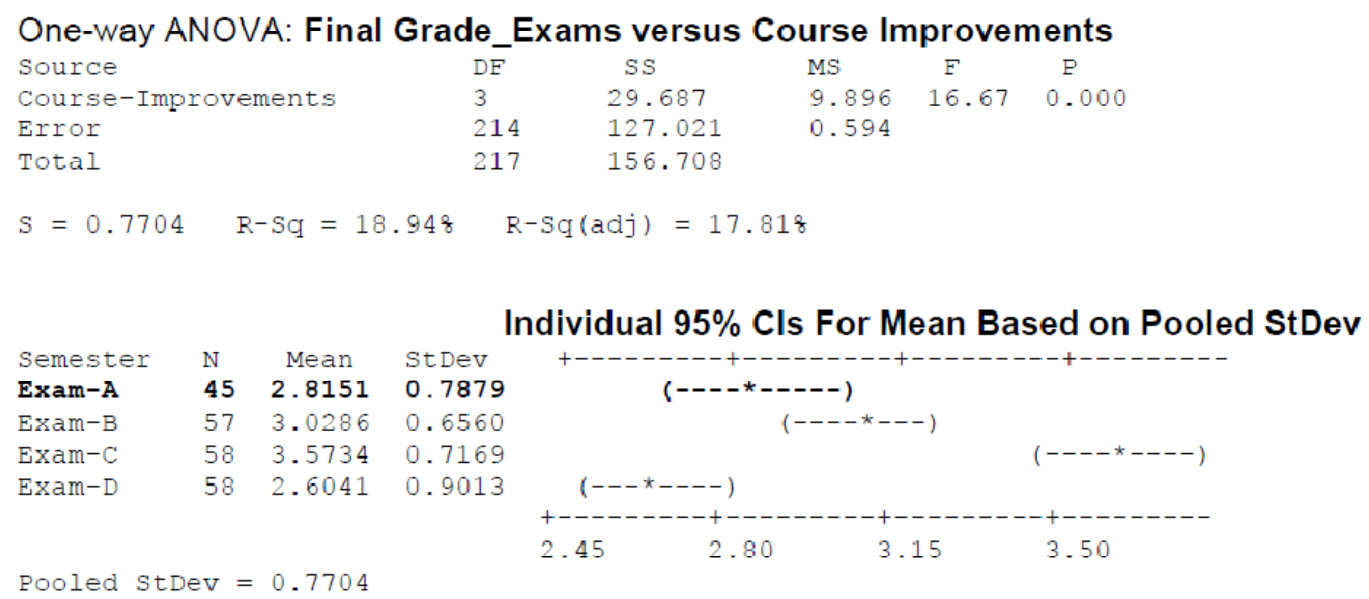

Figure 1: Intervals of confidence of the means of exams final grades. (Output from Minitab ANOVA function)

Nevertheless, assessing the effectiveness of the course improvements on the students' level of knowledge, in other words on the variable exams, through the analysis of multiple comparisons with Fisher test, we can suggest with $95 \%$ of confidence that the effectiveness was evidenced on the semester-C but no in the semester-B nor the semester-D (See Figure 2). 
Fisher 95\% Individual Confidence Intervals

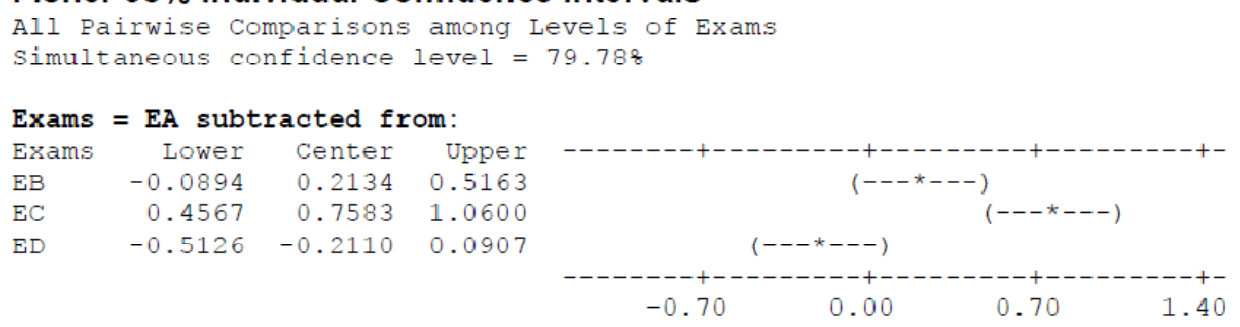

Figure 2: Multiple comparisons of exams final grades.

(Output from Minitab ANOVA-Comparison function)

Alike, the response variable named semester's project measured the enhancing professional skills as consequence of the course's improvements implemented in class. As shown on the Table 4, these measures were taken through the students' final grades of their semester's project under the same four scenarios analyzed for the variable exams. Likewise, these final grades were compared between all four scenarios. According to the variance analysis of the variable semester's project, there is evidence of statistical difference between the means of the semester's project final grades of these four scenarios $(\mathrm{p}<0.05)$ as theirs confidence intervals show in the Figure 3.

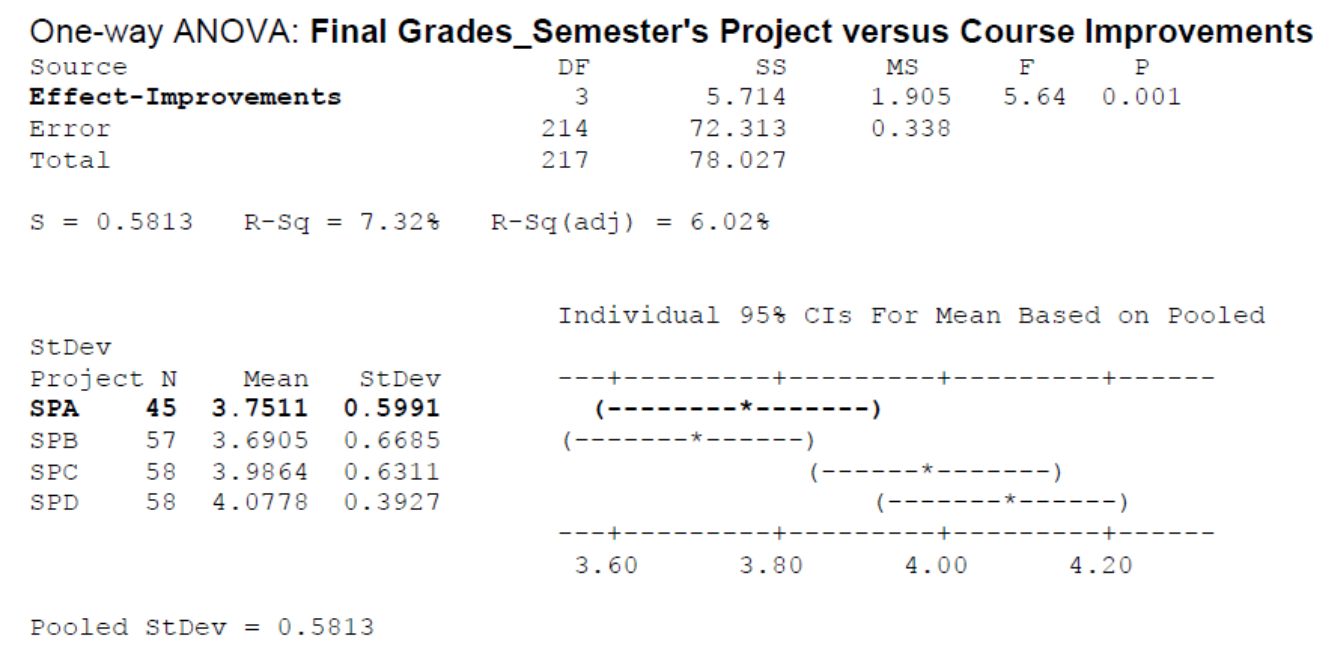

Figure 3: Intervals of confidence of the means of semester's project grades.

(Output from Minitab ANOVA function)

Nonetheless, assessing the effectiveness of the course improvements on the students' enhancing professional skills, in other words on the variable semester's project, through the analysis of multiple comparisons with Fisher test, we can suggest with $95 \%$ of confidence that the effectiveness of the improvements was evidenced on the semester-C and the semester-D (See Figure 4). 
Fisher 95\% Individual Confidence Intervals

All Pairwise Comparisons among Levels of TS

Simultaneous confidence level $=79.788$

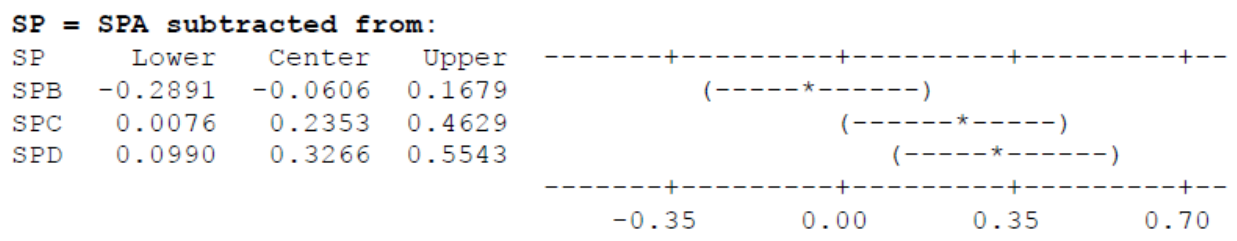

Figure 4: Multiple comparisons of semester's project final grades. (Output from Minitab ANOVA-Comparison function)

In short, it is noticeable that with the implementation of the course syllabus there was no statistically significant difference as shown by the comparison between the semester-A and semester-B, neither on the level of knowledge (variable exams, Figure 2) nor on the level of skills (variable semester's project, Figure 4). By the contrast, with the implementation of workshops in semesters $\mathrm{C}$ and $\mathrm{D}$, there was statistically significant difference on the level of skills as shown Figure 4, though on the level of knowledge it is weakly evident, whereby, there was difference with the semester-C but not with semester-D. The reason behind this dissimilar result may be explained as a result of "less effort law" to approve the course due to the inclusion of the workshops as grading component in the semester, which influences in the course final grade. Since a significant percentage of students, $44 \%$ of them work besides study, and $66 \%$ attend between 6 and 8 courses simultaneously in the same semester (as indicated in Table 2), it becomes in sign of low available time of students to study at home and prepare exams. Therefore, an easy way to approve the course is to work on the project and workshops mainly, and pay less attention to exams. Additionally, also it is observable quantitatively certain acceptance extent of the workshops as means to boost the students' performance in class, as also evidenced by the qualitative findings from the surveys and the test of Felder. These quantitative results are consequent with the students' preferences to learning methodologies that promote self-learning, linking theory and practice, and tackling innovative construction and management topics, as reflected the surveys. On the other hand there is no strong evidence of enhancing workshops on the level of knowledge of the students (on exams final grades). As closing remark, these results indicate a satisfactory extent of acceptance of these improvements implemented in the course, which were evidenced on the students' performance in class.

\section{Learned lessons and Conclusion}

This study focused on the redesign and improvement of the syllabus and the instruction strategy of Introduction to Construction course with the aim to enhance the academic performance of the students. It is necessary to be aware of the role that plays the engineering education within economic development in any country, thus the dimension and scope of a construction course syllabus, its learning strategy, and grading system affect contexts beyond the classroom borders. These instruction strategies must be conceived as a significant contribution to the economic and social Colombian context, besides boosting the performance of the students. The overreaching aim is to prepare the students for the technical challenges and management responsibilities that 
they will need to embrace, in the years to come, for the sustainable development of Colombian infrastructure system. As regards how to assess the course improvements in order to correct timely those ineffective strategies, this study showed as the grading system of a course becomes in a dynamic monitoring system to assess the influence first stage of a course Introduction to Construction in a country. Thus, this early indicator would be part of a broader monitoring system of the actual influence of the engineering education on the development of a country. As regards how much do these courses meet the current country's needs, it is recommendable to compare these early indexes of the students' performance with indexes of change in the longterm work practice of the engineers, with posterior implementation indexes of the acquired construction engineering concepts and skills. The effect of the educational effort in the actual work practice should be observed to favor the understanding of the work in her/his own discipline during the construction of a project, and the alignment of engineers around common goals and objectives.

By other side, based on the current state-of-the-art in construction and recommendations from researchers and Colombian educational boards, this study found that planning, scheduling, and cost estimating become fundamental topics of a construction course, which need to be taught in an integrated manner. Hence, the syllabus and the instruction strategies of an Introduction to Construction course must integrate in the same academic term, three main subjects: planning, scheduling, and cost estimating in construction projects. As regards how must the construction courses be in order to face these new challenges, this study showed that the society and the industry suggest a solution approach contextual rather than punctual, pervading beyond of the classroom boarders. Also, the students advocate approaching the class syllabus, exams, workshops, and homework based on real construction cases, data, and situations. The study also found that the preferences of the students on the education processes are consonant with the recommendations given by educational boards, such as instruction with methodologies that promote the self learning, mixing the theory with the practice, involving updated subjects of construction and management, with a practical approach, based on real situations, and the integration of computational tools in the classroom. The strategy that adjusts more to these conditions was identified as the use of workshops to consolidate class content. The use of this strategy has been demonstrated to strengthen the students' cognition and skills that result in an increased performance. Statistical analysis on the students' performance over four consecutive semesters demonstrated some positive effect of these new methods of instruction. As regard how does student respond to new strategies implemented in class, this study showed congruent findings to researches of Felder in engineering education, where engineering students want to base their knowledge on concrete knowledge rather than on abstract logic, and achieve the understanding of a topic with a learning strategy from the specific to the general concepts. The methodology and results of this study should be considered in further research, and implemented in other colleges and universities, especially in those emergent countries, since their application can result in the enhancement of an the infrastructure system of a country and the growth of its society and achieve better economic development indexes.

\section{References}

${ }^{[1]}$ Caro S., S.; "The Paradigm of Civil Engineering Education within the Colombian Context". Internacional Conference on Engineering Education. Valencia, Spain; July 21-25 de 2003.

${ }^{[2]}$ Asociación Colombiana de Facultades de Ingenería (ACOFI) (2006). "Educación en ingeniería frente a los Acuerdos de Libre Comercio." "Revista de Ingeniería.” No 24 Bogotá Junio 2006: ACOFI. 
${ }^{[3]}$ Creswell, J. W. (1999). "Mixed Method Research: Introduction and Application.” In T. Cijek (Ed.), Handbook of Educational Policy (pp 455-472). San Diego, CA: Academic Press.

${ }^{[4]}$ Morgan. D. (1998). "Practical Strategies for Combining Qualitative and Quantitative Methods; Applications to Health Research." Qualitative Health Research, 8, 362-376.

${ }^{[5]}$ Chinowsky, P. S., Meredith, J. E., (2000) "Strategic Corporate Management for Engineering." New York: Oxford University Press.

${ }^{[6]}$ Acevedo A., S. C. (2007). "Diseño de un Plan de Mejoramiento de los Procesos de Enseñanza-Aprendizaje de la Asignatura de Construccion II." Trabajo de grado para optar al título de Ingeniero Civil. Director Guillermo Mejia A. Escuela de Ingeniería Civil Universidad Industrial de Santander. Bucaramanga.

${ }^{[7]}$ Asociación Colombiana de Facultades de Ingenería (ACOFI), Instiituto Colombiano para el Fomento de la Educación (ICFES) (1996) “Actualización y modernización del currículo en Ingeniería Civil: documento final." Bogotá. ACOFI.

${ }^{[8]}$ Universidad Industrial de Santander (UIS) (2007) "Lineamientos para la Construcción del Plan de Desarrollo Institucional 2008-2018" Oficina de Planeación UIS. Bucaramanga Septiembre de 2007.

${ }^{[9]}$ Houser, R. (2009). "Counseling and Educational Research: Evaluation and Application." 2nd ed. Los Angeles: Sage Publications.

${ }^{[10]}$ Creswell, J. W. (2005) "Educational Research: Planning, Conducting, and Evaluating Quantitative and Qualitative Research." 2nd ed. Upper Saddle River, N.J.: Merrill.

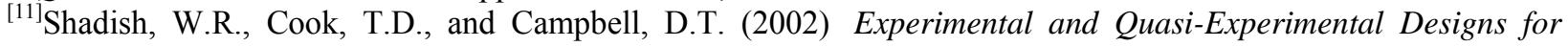
Generalized Causal Inference. Houghton-Mifflin, Boston, MA. 